\title{
Lusitanoneura gen. n. (Diptera: Mycetophilidae), including a new species from Portugal
}

\author{
Eugénia Ribeiro \& Peter Chandler
}

\begin{abstract}
Ribeiro, E. \& Chandler, P. 2007: Lusitanoneura gen. n. (Diptera: Mycetophilidae), including a new species from Portugal. — Entomol. Fennica 18: 138-143.

A new genus of fungus gnats Lusitanoneura gen. n. (Diptera: Mycetophilidae), allied to Ectrepesthoneura Enderlein, 1911, is described to include Ectrepesthoneura chandleri Caspers, 1991 from Crete and Cyprus and L. grandolensis sp. n. from Portugal. These species are considered congeneric with each other but not with the bulk of species hitherto assigned to Ectrepesthoneura.

E. Ribeiro, Departamento de Biologia Animal/Centro de Biologia Ambiental, Faculdade de Ciências da Universidade de Lisboa, Campo Grande, Bloco C2, 1749-016, Portugal.E-mail: eribeiro@fc.ul.pt

P. Chandler, 606B Berryfield Lane, Melksham, Wilts SN12 6EL, UK. E-mail: Chandgnats@aol.com
\end{abstract}

Received 20 April 2006, accepted 20 September 2006

\section{Introduction}

A programme of Malaise trapping at sites in Portugal has been carried out in recent years by one of us (ER) and material was collected into 70 per cent ethanol. At one of these sites both sexes of a dark coloured fungus gnat, which was evidently undescribed, were found. This species had the wing venation and most other characters typical of the genus Ectrepesthoneura Enderlein, 1911 but obviously differed in structure of its male genitalia from any previously known species. It did, however, have some significant characters, especially of the male genitalia, in common with $E$. chandleri Caspers and these two species are considered to differ sufficiently from the other species assigned to Ectrepesthoneura to propose a new genus to include them. It is probable that some other species placed in Ectrepesthoneura, such as E. gracilis Edwards, 1928 will be found to deserve such a change of status when the world fauna of this group is better known.

\section{Genus description}

\section{Lusitanoneura gen. n. Ribeiro \& Chandler}

Diagnosis. Similar to Ectrepesthoneura in the following characters: antennal flagellum slender; thorax with mediotergite and laterotergite bare; fine tibial setulae not in regular rows; wing with macrotrichia absent from the membrane; vein $\mathrm{Sc}$ ending in $\mathrm{R}$; vein $\mathrm{R}_{1}$ less than twice as long as crossvein $\mathrm{r}-\mathrm{m}$; vein $\mathrm{R}_{4}$ present and ending in $\mathrm{R}_{1}$; $\mathrm{CuA}$ branching very close to the base of the wing. Differing from Ectrepesthoneura as follows: body and legs of more slender build; male mid tibia unmodified, lacking any swelling or secondary sexual characters in arrangement of setae; gonocoxites separate medially (fused at least basally on ventral margin in Ectrepesthoneura except E. gracilis); gonostylus large but set subapically with gonocoxites broadly extended dorsally (set close to apical margin of gonocoxites in Ectrepesthoneura); gonostylus broad medially, 
but extended dorsally and ventrally as narrower lobes (of various form in Ectrepesthoneura but usually more compact and without elongate lobes); tergite 9 of various form but differing from that in Ectrepesthoneura which usually has it large and broadly enclosing the genitalia dorsally and laterally (except $E$. gracilis which has it short and small).

Description. Male. Head with short bristling. Ocelli three, in a transverse row, the laterals situated almost as far from the eye margin as from the median ocellus. Antenna slightly upturned, with scape and pedicel short; flagellum 14 segmented, slender, with elongate flagellomeres, bearing short hairs; apical flagellomere slender with small apical protuberance. Proboscis short; palpus about as long as head, with four obvious palpomeres, the two basal short and thick and about as long as broad, the penultimate more elongate and the terminal palpomere long and slender.

Thorax with bristling on the prothorax, mesonotum and scutellum; bristling on mesonotum including acrostichal and uniserial dorsocentral series and longer setae near side margins. Pleura otherwise, laterotergite and mediotergite bare. Katepisternum larger than anepisternum, both irregularly quadrate; laterotergite elongate oval, shallowly raised medially. Legs long and slender. Tibial spurs elongate, 1:2:2. Mid tibia without any swelling or sensory area apparent. Mid and hind tibiae with series of black setae, shorter than width of tibia. Wing membrane with uniform covering of microtrichia, macrotrichia absent. Costa and radial veins thickened and darker than other veins. Costa and radial veins bearing short setae, the veins of median and posterior forks with inconspicuous small setulae. Costa extending nearly or quite half distance from tip of $\mathrm{R}_{5}$ to that of $\mathrm{M}_{1}$. Vein Sc long, ending in $\mathrm{R}$. Vein $\mathrm{R}_{4}$ present, short and vertical, ending in $\mathrm{R}_{1}$, forming a small elongate rectangular radial cell. Crossvein $\mathrm{r}-\mathrm{m}$ diagonal, long but shorter than both $\mathrm{R}_{1}$ and the stem of median fork. Branches of posterior fork sessile, beginning close to base of wing, branching at their point of contact with the base of vein tb. Haltere yellow.

Abdomen with segments 1-6 normally developed, with tergites and sternites of similar length. Tergites of segments 7 and 8 are narrow strips while their sternites are more elongate; sternite 8 broad and apically truncate, forming a flap under the genitalia. Tergite 9 longer than broad, at least partly covering the base of the genitalia dorsally but differing in form in the two included species. Gonocoxites large and broad laterally, but medially separate to the base, without any sclerotised bridge, linked internally only by gonocoxal apodemes linked to parameres of aedeagus. Gonostylus large but set subapically and not extending much beyond tip of gonocoxites distally; broad medially, broad, produced to a slender lobe at both dorsal and ventral edges. Cerci short, small, in close contact with aedeagus. Aedeagus with narrow median sclerotised apodeme and weakly sclerotised parameres laterally.

Female. Very similar to male. Abdomen with segment 7 about half as long as preceding segments; tergites 8 and 9 narrow; sternite 8 longer, deeply emarginate medially, with rounded lateral lobes bearing some marginal setae. Cercus twosegmented; basal segment broad, elongate; apical segment short, rounded.

Type-species: Lusitanoneura grandolensis sp. n.

Etymology. The genus is named to reflect the known distribution of the newly described species, from Lusitania, Latin for Portugal.

\section{Species descriptions}

\section{Lusitanoneura grandolensis sp. $\mathbf{n}$. Ribeiro \& Chandler}

Material examined. Holotype male, Portugal, Herdade da Ribeira Abaixo, near Grândola (south-west of Alentejo), found at 150-240 m a.s.1, 22.IV.2001-19.V.2001, Malaise trap, leg. E. Ribeiro. Paratypes (all same locality as holotype): 1 đิ 1 O, 18.XII.1997 - 6.I.1998; 1 ठૈ, 03.XII.1998-31.I.1999; 1 +，21.XI.1999-20. XII.1999 (all ex Malaise traps, leg. E. Ribeiro). All type material deposited in Departamento de Biologia Animal/Centro de Biologia Ambiental, Faculdade de Ciências da Universidade de Lisboa, Portugal.

Diagnosis. This species agrees with $L$. chandleri in external characters and lacking the mid tibial organ. It also has a gonostylus of similar structure, being produced into slender lobes on its ven- 

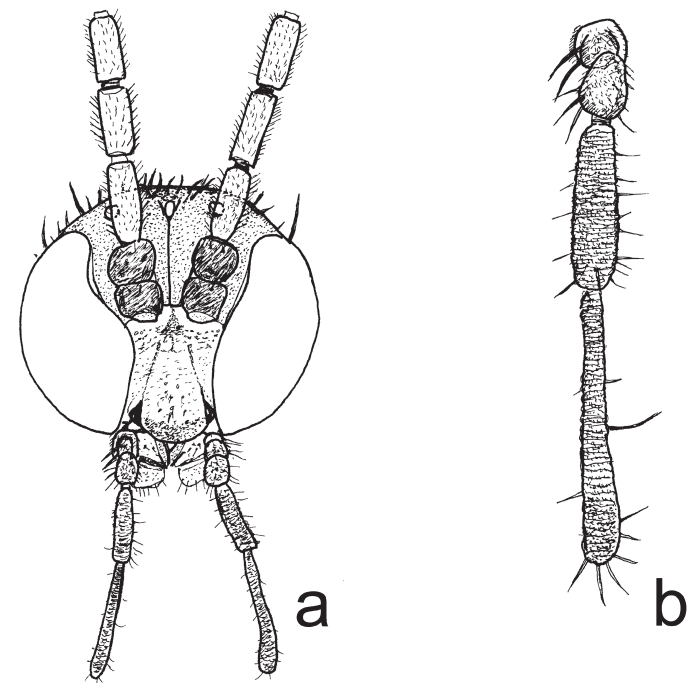

Fig. 1. Lusitanoneura grandolensis sp. n. male head (height of head $0.6 \mathrm{~mm}$ ). - a. Anterior view of head, including basal three flagellomeres of antennae. - b. Palpus.

tral and dorsal margin. It does, however, obviously differ in the form of tergite 9, which is simple in the new species but produced medially into an elongate apically rounded process in L. chandleri.

Description. Male. Head (Fig. 1a) dark brown, with short dark bristling. Antenna entirely dark; scape and pedicel about as long as broad; flagellum slender, longer than head and thorax together; flagellomeres about 3 times as long as broad, bearing short pale hairs; apical flagellomere a little longer. Proboscis short; palpus (Fig. 1b) about as long as eye, with two basal palpomeres about as long as broad, the penultimate more elongate and the terminal palpomere as long as the preceding palpomeres together, mostly slender but slightly swollen on apical quarter.

Thorax dark brown with brownish yellow bristling on the prothorax, mesonotum and scutellum; acrostichals and dorsocentrals short, setae near side margins of mesonotum longer; two pairs of strong scutellars. Pleura, laterotergite and mediotergite bare. Legs yellowish brown, coxae darker brown, with all bristling dark. Tibial spurs yellow; outer spurs on mid and hind tibiae more than twice as long as width of tibial apex. Mid tibia with 2-4 $a$ and $d$ setae and a series of very short $p$ setae; hind tibia with 6-9 $a, 3-6 p-d$ and

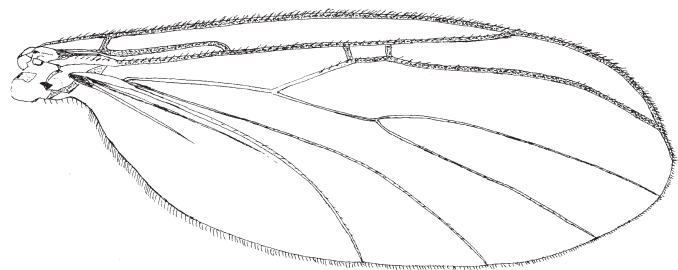

Fig. 2. Wing of Lusitanoneura grandolensis sp. $\mathrm{n}$. (length $3.3 \mathrm{~mm}$ ).

series of very short $p$ and $v$ setae. Wing clear (Fig. 2). Costa and radial veins thickened and brownish, other veins yellowish. Costa and radial veins bearing short setae, the series on $\mathrm{R}_{5}$ extending back to apical half of crossvein r-m. Costa extending nearly half distance from tip of $\mathrm{R}_{5}$ to that of $\mathrm{M}_{1}$. Haltere yellow.

Abdomen entirely dark, including genitalia, but with bristling pale. Tergite 9 (Fig. 3c) longer than broad, apically truncate and slightly emarginate medially on apical margin; covering the base of the genitalia dorsally, but relatively small, only about half as long as gonocoxites. Gonocoxites (Fig. 3a) broad laterally, with apical margins mainly straight-edged but produced to a point apically near their dorsal margin; medially separate to the base. Gonostylus (Fig. 3b) laterally flattened, broad and setose basally with a slender apically asetose lobe at dorsal and ventral edges; basal part with a rounded protuberance bearing long setae, otherwise with scattered fine setae. Aedeagus closely apposed to small cerci (Fig. $3 d$ ), with narrow median sclerotised apodeme and weakly sclerotised parameres.

Female. Very similar to male, apart from structure of abdomen as described for genus. Sternite 8 with lateral lobes bearing some strong marginal setae (Fig. 4).

Wing length $3.3 \mathrm{~mm}$ (male), $3.5 \mathrm{~mm}$ (female).

Etymology. The new species is named for the type locality.

Distribution. The locality Herdade da Ribeira Abaixo (38 8' N, 8 $8^{\circ} 33^{\prime} \mathrm{W}$, UTM 29SNC3717) is a farm of 221 hectares, situated at Santa Margarida da Serra in the Grândola mountains, $7 \mathrm{~km}$ south of the city of Grândola.

Biology. Unknown. The predominant biotope where the holotype and one female paratype were found is at 150-240 metres altitude and comprises a cork oak (Quercus suber) grove, typical 
Fig. 3. Male genitalia of Lusitanoneura grandolensis sp. $\mathrm{n}$. (length of gonocoxites $0.7 \mathrm{~mm}$, length of tergite $90.4 \mathrm{~mm}$ ). $-a$. Ventral view. - b. Lateral view of gonostylus. $-c$. Tergite 9. - d. Ventral view of aedeagus, cerci slightly displaced behind.
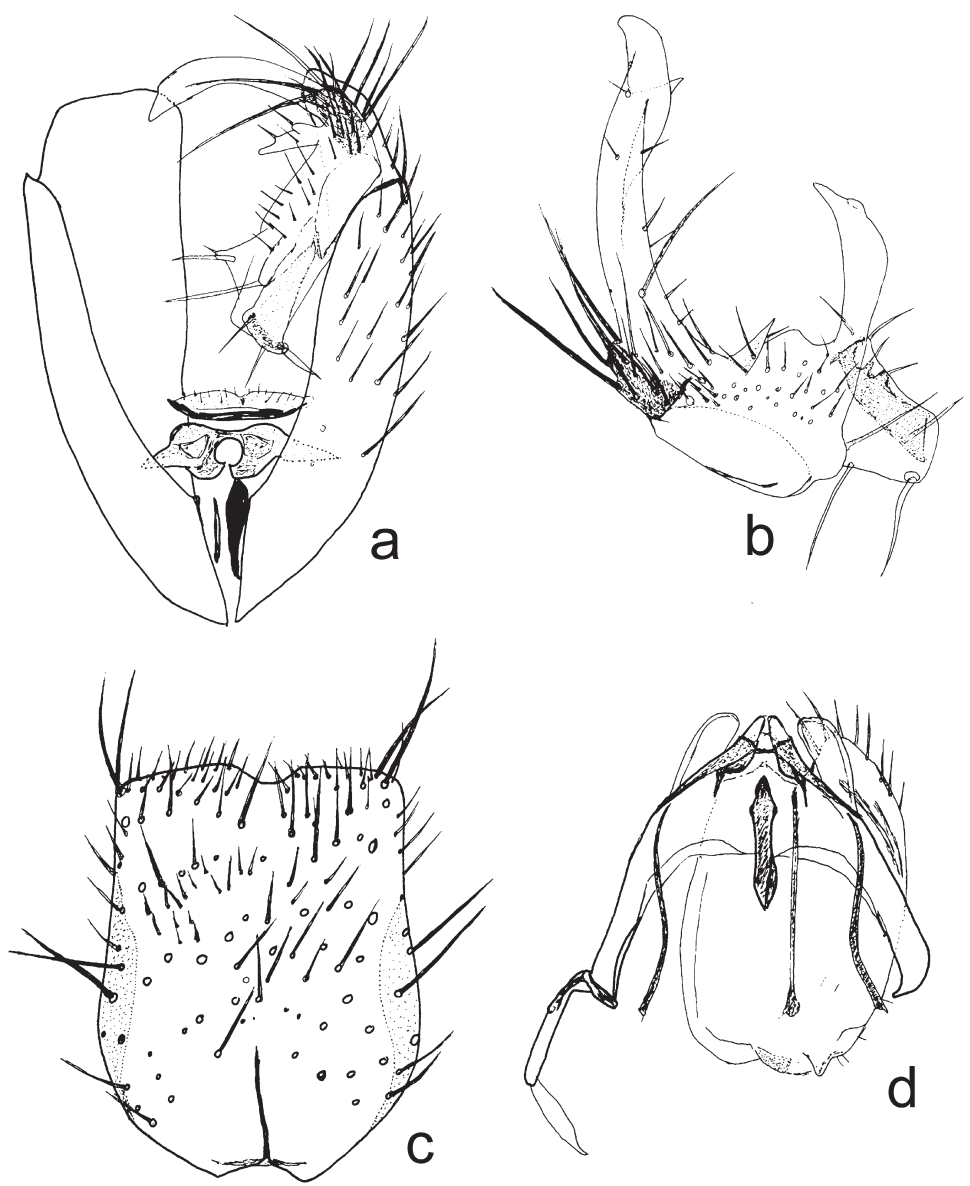

of the Mediterranean climate of this area. This site also has a significant presence of Cistus salvifolius, C. ladanifer and Lavandula luisieri. The other earlier collected specimens were in a different biotope on the same farm, also a cork oak grove but associated with a meadow.

\section{Lusitanoneura chandleri (Caspers, 1991), comb. n.}

\section{Ectrepesthoneura chandleri}

Caspers, 1991: 325, Figs 7-10.

Additional material examined (in P.J. Chandler collection unless otherwise stated). GREECE, Crete, north of Omalos, 1,500 m a.s.1, 17.V.1982, small gorge, 1 ô, leg. I.F.G. McLean; Crete, west of Mesa Potami, 19.V.1982, flowing stream in cultivated area, 1 q, leg. I.F.G. McLean; CY-

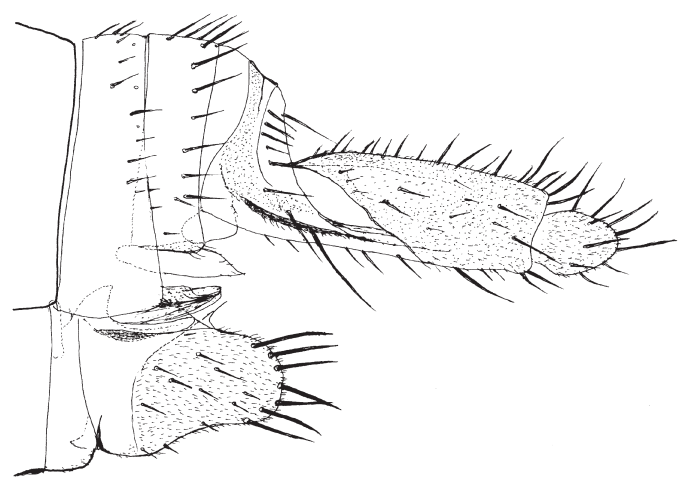

Fig. 4. Lusitanoneura grandolensis sp. n., lateral view of ovipositor (length of basal segment of cercus 0.25 $\mathrm{mm})$.

PRUS, Platres, 1,400 m a.s.1, 21.V.1983, 1 ㅇ, beside and above Caledonian Falls, Golden Oak forest and plane trees by the stream, leg. I.F.G. McLean; Akrounta Forest, 24.IV.2002, 1 ô, leg. 
P. Gatt (private collection, Malta); Troodos Mountains, Troodos env., 11.IV.2002, 1 q, pine forest, leg. J. Roháček (Silesian Museum, Opava, Czech Republic).

Remarks. Caspers (1991) described this species from a single male from Crete and referred to a male and female from Cyprus, but as the ovipositor of the female was in poor condition he did not describe or figure it. The fresh material from Crete and Cyprus reported by Chandler et al. (2006) and also listed above enables this to be figured here.

In Caspers' description the reference to third segment of palpi is presumably to the terminal or 4th distinct palpomere. The tibial spurs are more strongly developed than in L. grandolensis, 3-4 times as long as apical width of tibia. Caspers referred to the slender curved process (termed by him semilunar) from the inner surface of the gonocoxites (as basimeres), a structure that is not developed in the Portuguese species. His description and figure of the gonostylus does not indicate the presence of the narrow ventral lobe, which was probably reflexed dorsally in situ in the specimen he figured. The male genitalia are figured here (Fig. 5a-b), both to show this and for comparison with the new species.

Description of female. Very similar to male, differing in the genital characters which are similar to the female of $L$. grandolensis: abdominal segment 7 about half as long as preceding segments; ovipositor (Fig. 5c) yellowish brown with tergites 8 and 9 narrow; sternite 8 longer, deeply emarginate medially, with rounded lateral lobes bearing fine marginal setae. Cercus two-segmented; basal segment broad, elongate; apical segment short, rounded. Wing length of females $3.7-3.8 \mathrm{~mm}$.

\section{Discussion}

The species here assigned to the new genus Lusitanoneura run to the genus Ectrepesthoneura Enderlein in the key to family Mycetophilidae by Søli et al. (2000), due to possessing the characters cited as in common with it in the above generic diagnosis. The practically sessile posterior fork has been used to define Ectrepesthoneura as distinct from the allied genus Tetragoneura Winnertz. As

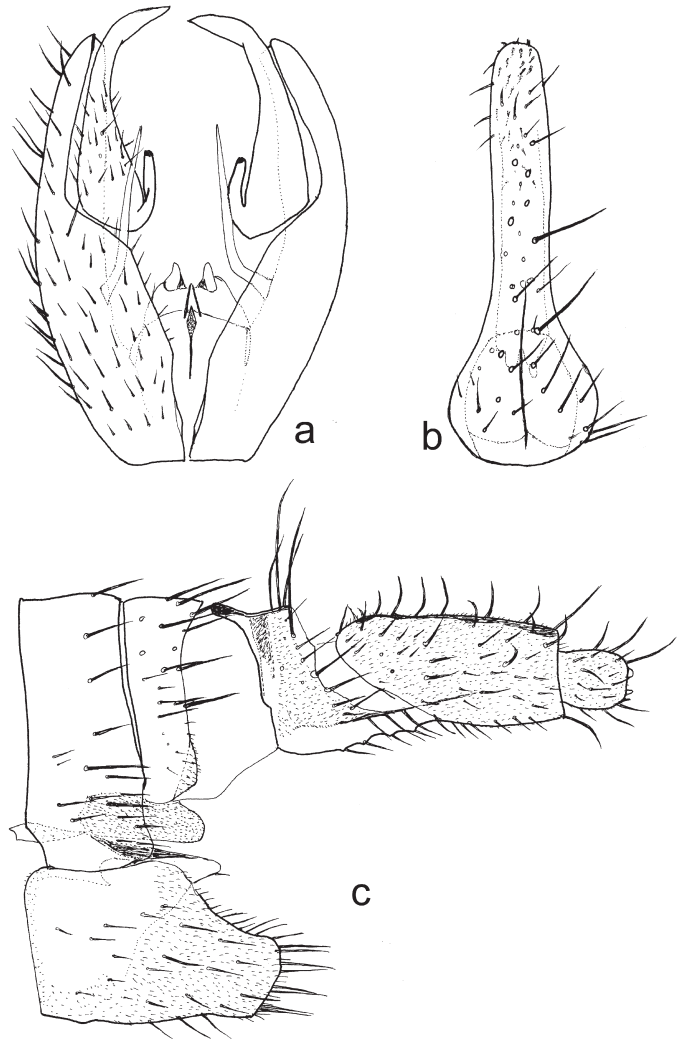

Fig. 5. Lusitanoneura chandleri (Caspers). - a. Ventral view of male genitalia (length of gonocoxites $0.6 \mathrm{~mm}$ ). -b. Male tergite 9 (length $0.6 \mathrm{~mm}$ ). - c. Lateral view of ovipositor (length of basal segment of cercus 0.2 $\mathrm{mm})$.

indicated by Caspers (1991) this is a plesiomorphous character in Mycetophilidae, although present in relatively few extant genera. The phylogenetic conclusions of Søli (1997) acknowledge the primitive nature of this character in Drepanocercus Vockeroth but the position of Ectrepesthoneura in the trees in Figs 45 and 46 of that work suggests that this could be a secondary development in this genus, although in the second of these trees it does appear in a basal position among the genera of Leiinae.

The majority of species now placed in Ectrepesthoneura appear to constitute a monophyletic group as discussed by Chandler (1980) but the Mediterranean species E. gracilis Edwards, 1928 was indicated to differ in structure of genitalia and habitus, being more slender with longer legs than other species of the genus and was not in- 
cluded in the diagnosis. When Caspers (1991) described E. chandleri it was apparent that it was also divergent from the typical form of the genus; it resembled $E$. gracilis in form but again differed strongly in structure of genitalia and in lacking a sensory area (tibial organ) on the male mid tibia, which is present in gracilis as in other species of the genus.

It is possible that Ectrepesthoneura gracilis is related to the new genus. It also has the gonocoxites separate medially. The structure of the ovipositor figured by Chandler and Gatt (2000) is very similar to that of Lusitanoneura grandolensis, agreeing in the presence of strong marginal setae on sternite 8 , while these setae are finer in L. chandleri. It is, however, excluded at present because it possesses a male mid tibial organ and there are differences in the male genitalia such as the form of the gonostylus. A similar ovipositor with strong setae on sternite 8 is also found in some other Gnoristinae including Boletina trivittata (Meigen, 1818) and in the recently discovered female of Creagdhubhia mallochorum Chandler, 1999 (Chandler 2006).

The subfamily or tribal position of these genera is still not resolved. On the basis of the wing venation they have traditionally been placed in Leiini (or Leiinae) but Väisänen (1986) strongly argued for their inclusion in Gnoristinae (treated as tribe Gnoristini by some authors) and we have followed him in the assignment of genera, including in the systematic arrangement in Fauna Europaea (Chandler 2004). As indicated above Søli (1997) suggested that they should be retained in Leiini on the basis of his phylogenetic conclusions based on non-genital characters while suggesting that Gnoristini was a plesiomorphic as- semblage that could not be justified phylogenetically. Further study is necessary including all characters to resolve relationships.

Acknowledgements. We are grateful to the collectors who referred the new material of $L$. chandleri to us. The work was partially financed by Centro de Biologia Ambiental.

\section{References}

Caspers, N. 1991: New and remarkable species of Mycetophiloidea (Diptera, Nematocera) from the Mediterranean region. - Spixiana 14: 321-338.

Chandler, P. J. 1980: The European and eastern Nearctic fungus-gnats in the genus Ectrepesthoneura (Mycetophilidae). - Syst. Entomol. 5: 27-41.

Chandler, P. J. 2004: Mycetophilidae. In: de Jong, H. (ed.), Fauna Europaea: Diptera, Nematocera. - Fauna Europaea version 1.1. [www document] URL http:// www.faunaeur.org.

Chandler, P. J. 2006: Additions and changes to the British fauna of fungus gnats (Diptera: Mycetophilidae). Bt. J. Ent. Nat. Hist. 19: 77-89.

Chandler, P. J. \& Gatt, P. 2000: Fungus Gnats (Diptera: Bolitophilidae, Keroplatidae and Mycetophilidae) from the Maltese islands. - Studia Dipterol. 7: 69-81.

Chandler, P. J., Bechev, D. \& Caspers, N. 2006: The Fungus Gnats (Diptera: Bolitophilidae, Diadocidiidae, Ditomyiidae, Keroplatidae and Mycetophilidae) of Greece, its islands and Cyprus. - Studia Dipterol. (2005) 12: 255-314.

Søli, G. 1997: On the morphology and phylogeny of Mycetophilidae, with a revision of Coelosia Winnertz. Entomol. Scand., Suppl. 50: 1-139.

Søli, G. E. E., Vockeroth, J. R. \& Matile, L. 2000: Families of Sciaroidea. - In: Papp, L. \& Darvas, B. (eds), Contributions to a Manual of Palaearctic Diptera, Appendix: 604. Science Herald, Budapest.

Väisänen, R. 1986: The delimitation of the Gnoristinae: criteria for the classification of recent European genera (Diptera, Mycetophilidae). - Ann. Zool. Fenn. 23: 197-206. 